\title{
Excess Mortality in a Nephrology Clinic during First Months of Coronavirus Disease-19 Pandemic: A Pragmatic Approach
}

Lada Trajceska ${ }^{1 *}$, Aleksandra Canevska ${ }^{1}$, Nikola Gjorgjievski ${ }^{1}$, Mimoza Milenkova ${ }^{1}$, Adrijana Spasovska-Vasilevska ${ }^{1}$ Galina Severova-Andreevska ${ }^{1}$, Daniela Mladenovska ${ }^{1}$, Vladimir Pusevski ${ }^{1}$, Maja Kuzmanovska ${ }^{2}$, Elizabeta Janceska ${ }^{2}$, Golubinka Bosevska ${ }^{2}$, Irena Rambabova-Busljetik ${ }^{1}$, Gjulsen Selim ${ }^{1}$ Goce Spasovski ${ }^{1}$

${ }^{1}$ University Clinic for Nephrology, Ss. Cyril and Methodius University, Skopje, Republic of Macedonia, Balkans; ${ }^{2}$ Laboratory for Virology, Institute of Public Health, Skopje, Republic of Macedonia, Balkans

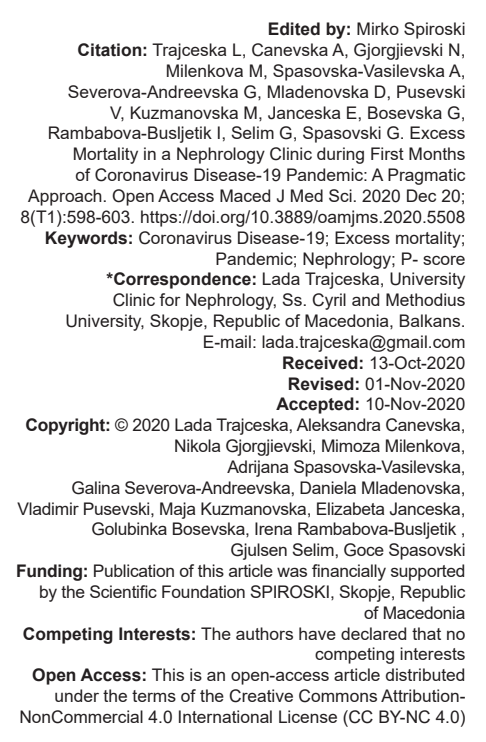

\section{Abstract}

BACKGROUND: Excess mortality is defined as mortality above what would be expected based on the non-crisis mortality rate in the population of interest.

AIM: In this study, we aimed to access weather the coronavirus disease (COVID)-19 pandemic had impact on the in-hospital mortality during the first 6 months of the year and compare it with the data from the previous years.

METHODS: A retroprospective study was conducted at the University Clinic of Nephrology Skopje, Republic of Macedonia. In-hospital mortality rates were calculated for the first half of the year (01.01-30.06) from 2015 until 2020 as monthly number of dead patients divided by the number of non-elective hospitalized patents in the same period. The excess mortality rate ( $p$-score) was calculated as ratio or percentage of excess deaths relative to expected average deaths: (Observed mortality rate-expected average death rate)/expected average death rate * $100 \%$.

RESULTS: The expected (average) overall death mortality rate for the period 2015-2019 was $8.9 \%$ and for 2020 was $15.3 \%$. The calculated overall excess mortality in 2020 was $72 \%\left(p_{\text {score }} 0.72\right)$.

CONCLUSION: In this pragmatic study, we have provided clear evidence of high excess mortality at our nephrology clinic during the $1^{\text {st }}$ months of the COVID-19 pandemic. The delayed referral of patients due to the patient and health care system-related factors might partially explain the excess mortality during pandemic crises. Further analysis is needed to estimate unrecognized probable COVID-19 deaths.

\section{Introduction}

The World Health Organization (WHO) has recognized thespread of coronavirus disease(COVID)-19 as a pandemic in March 2020 [1]. Authorities worldwide have implemented preventive measures, restrictions, lockdowns, and facility closures to slow the spread of the disease. Still, over 690,000 deaths worldwide were registered [2]. Excess mortality is defined by WHO [3] as: "Mortality above what would be expected based on the non-crisis mortality rate in the population of interest. Excess mortality is, thus, mortality that is attributable to the crisis conditions. It can be expressed as a rate (the difference between observed and non-crisis mortality rates), or as a total number of excess deaths." It is used to measure the mortality impact of a crisis when not all causes of death are known.

Hospital mortality has been used to assess the quality of care in our University Clinic of Nephrology
(UCN). The annual in-hospital mortality rate which is being regularly referred to as the Ministry of Health $(\mathrm{MOH})$, has been stable around $6 \%$ in the previous several years [4]. This healthcare unit is providing nephrology tertiary care for around two million citizens. It treats over 20000 outpatients per year and more than 2300 in-hospital patients. It provides over 500 emergency dialysis sessions, over 1500 vascular access interventions covering complications for almost all hemodialysis patients in the country [5]. Annually hundreds of renal [6], [7] and prostate biopsies are performed as elective or urgent procedures. Almost all Macedonian chronic kidney disease (CKD) patients initiate chronic hemodialysis program at our clinic and referred to local dialysis centers thereafter. Annually that number is around 300 patients [8].

The COVID-19 pandemic did not spare Macedonia. The first recognized case was known to be imported from Italy and laboratory confirmed on $26^{\text {th }}$ of February 2020 [9]. The $\mathrm{MOH}$ closely monitored and prevented the spreading of the virus with implemented 
strict protocols in the social area and the health care system. Patients were informed and medical doctors instructed to refer patients to tertiary level only in emergency. Substantial behavioral restrictions have been imposed mostly because of the decision to prioritize preventing clusters from spawning. Even though, in the end of June, more than 6000 people were infected and 298 patients had died [2]. In this period at our hospital, starting from March, all previously scheduled out-patient referrals and elective in-hospital diagnostic (biopsies) or vascular access interventions (arteriovenosus fistula/tunnelled catheter creations) were cancelled or postponed. Patients with nephrology emergency were referred from all over the country and screened for COVID-19 at admission by clinical examination and epidemiological questionnaire. Patients with high risk were isolated and tested with the polymerase chain reaction (PCR) technique. If positive, those were transferred to the dedicated COVID-19 hospitals. Hospital policy applied written protocol measures for prevention of spreading the disease and adequate stuff and patents protective equipment used according to the current $\mathrm{MOH}$ recommendations on COVID-19 disease. In hospital, mortality was monitored and notified.

In this study, we aimed to access whether the COVID-19 pandemic had an impact on in-hospital mortality during the first 6 months of the year and compare it with the data from the previous years.

\section{Methods}

A retro-prospective study was conducted at UCN Skopje, Republic of Macedonia. A pragmatic approach was used to determine in-hospital mortality rates for the first half of the year (01.01-30.06) from 2015 until 2020. The mortality rates were estimated as monthly number of dead patients divided by the number of nonelective hospitalized patents in the same period. The data were extracted from the hospital registry, the National Integrated Health Information System-My Term (Moj Termin) [10], and the diagnosis-related group system [11], both based on a central database of all public health services in the country for the hospital patients. All the patients that were registered for hospitalization at our clinic for any reason in the 6 years were analyzed; no patients were excluded from the study. Elective in-hospital procedures (programmed creation of permanent vascular access - AV fistula or tunneled central venous catheter, prostate biopsy, renal [native or transplant] biopsy, potential kidney donor, and recipient evaluations) were canceled during pandemic, which resulted in minimizing the number of hospitalizations. Furthermore, minor vascular access interventions were performed as single day ambulatory procedures. Therefore, the mortality rates for the previous years were also estimated only for non-elective hospitalizations. In addition, deaths were analyzed by time frame of occurrence in $<24$ and $48 \mathrm{~h}$ from admission. The number of initial hemodialysis patents was calculated per state population [5], [12].

The real-time reverse transcriptase-PCR (RT-PCR) technique was used to detect severe acute respiratory syndrome coronavirus 2 (SARS-CoV-2) from nasopharyngeal and oropharyngeal swabs as specimen from each patient. All tests were performed at the Laboratory for Virology, Institute of Public Health (IPH) according to protocols available on the WHO website [13]. Patients were tested at the discretion of the clinicians if clinical criteria or/and epidemiological linkage to COVID-19 disease were positive for close contact, prior, at admission, or during the hospital stay.

Statistical analysis was performed with SPSS 16.0 for Windows: Continuous variables are shown as mean values and categorical as percentages. The excess mortality rate ( $p$-score) was calculated as ratio or percentage of excess deaths relative to expected average deaths: (Observed mortality rate-expected average death rate)/expected average death rate $x$ $100 \%$. The observed mortality rates were from 2020 and the expected from the period 2015 to 2019.

\section{Results}

During the previous 5 years, there were more than 1000 patients admitted each year in the first 6 months of the year (Table 1). The hospitalizations due to any elective procedure ranged from $20 \%$ to $38 \%$ and the rest $(60-80 \%)$ were for urgent or other nephrological treatment. The half-annual all-cause mortality rates in non-elective cases were stable at $7.4-10.9 \%$. Deaths in the first $24 \mathrm{~h}$ of admission ranged between $2.8 \%$ and $4.2 \%$ and in the first $48 \mathrm{~h}$ from $2.8 \%$ to $5.3 \%$. In the current year of 2020 , the admissions were rather halved in the first 6 months (497), including only $7 \%$ of elective cases. Almost exclusively (93\%) were patients admitted for urgent or other non-delayable treatments. In 2020, the mortality rates raised up to $15.3 \%$ for all non-elective admissions, almost doubling for the $24 \mathrm{~h}$ deaths (6.0\%) and for the deaths in the first $48 \mathrm{~h}(9.9 \%)$. As for the surviving patients, the number of incident dialysis patients through the period of all 6 years was stable around 150 patients or $75 \times 10^{-6}$ per state population.

The expected (average) overall death mortality rate for the period 2015-2019 was 8.9\%. For the patients that died in the first $24 \mathrm{~h}$ of admission, the average mortality rate for the same 5 years period was $3.3 \%$ and for the dead in the first $48 \mathrm{~h} 4.0 \%$. The calculated overall excess mortality was $72 \%\left(p_{\text {score }} 0.72\right)$, then $79 \%$ $\left(p_{\text {score }} 0.79\right)$ for mortality in the first 24 and $102 \%\left(p_{\text {score }}\right.$ 1.02 ) in the first $48 \mathrm{~h}$, respectively, for 2020 (Figure 1). Out of all 71 dead patients, $28(40 \%)$ died in the first 24 $h$ and $46(65 \%)$ in the first 48 h in 2020. 
Table 1: Admissions, mortality rates, and incident dialysis patients in the first 6 months from 2015 to 2020

\begin{tabular}{|c|c|c|c|c|c|c|}
\hline Year $\left(01^{\text {th }}\right.$ January $-30^{\text {th }}$ June $)$ & 2015 & 2016 & 2017 & 2018 & 2019 & 2020 \\
\hline All hospitalizations & 1191 & 1250 & 1286 & 1061 & 1132 & 497 \\
\hline Non-elective (\%) & $757(64)$ & $856(68)$ & $819(64)$ & $659(62)$ & $905(80)$ & $463(93)$ \\
\hline Elective (\%) & $434(36)$ & $394(31)$ & $467(36)$ & $402(38)$ & $227(20)$ & $34(7)$ \\
\hline Mortality rates in non-elective cases (\%) & $60(7.9)$ & $74(8.6)$ & $61(7.4)$ & $72(10.9)$ & $88(9.7)$ & $71(15.3)$ \\
\hline Death cases (first 24 h) (\%) & $28(3.7)$ & $24(2.8)$ & $23(2.8)$ & $28(4.2)$ & $29(3.2)$ & $28(6.0)$ \\
\hline Death cases (first 48 h) (\%) & $31(4.1)$ & 30 (3.5) & $23(2.8)$ & $35(5.3)$ & $39(4.3)$ & $46(9.9)$ \\
\hline In-hospital incident dialysis patients (per state population $\left.\times 10^{-6}\right)(\%)$ & $149(74)$ & $157(78)$ & $168(84)$ & $147(73)$ & $160(80)$ & $149(74)$ \\
\hline
\end{tabular}

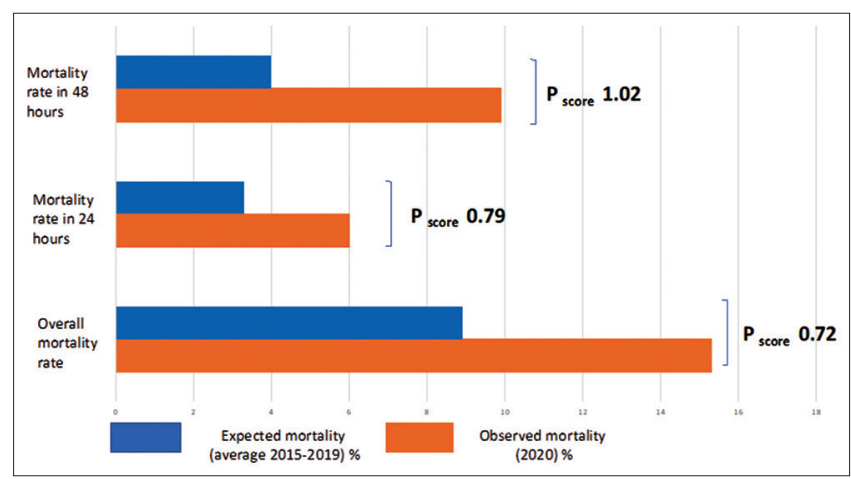

Figure 1: Excess mortality p-scores for 2020 regarding average mortality for 2015-2019.

Figure 2 compares the monthly in-hospital death rates for non-elective admissions in 2020 (red line), against each of the five preceding years. Soon after the detection of the first COVID-19 community case $\left(26^{\text {th }}\right.$ of February), death rates increased rapidly. In $<4$ weeks, they almost doubled from $14.8 \%$ in March to $28.3 \%$ in April. In the following 2 months, the death rates were higher than $20 \%$, exceeding the average rates in the same months in the previous 5 years (Table 2).

Table 2: Increasing monthly mortality rates in 2020 versus average death rates in 2015-2019

\begin{tabular}{lllllll}
\hline Mortality $(\%)$ & January & February & March & April & May & June \\
\hline 2015 & 9.6 & 9.1 & 4.1 & 8.0 & 8.8 & 8.1 \\
2016 & 11.4 & 9.8 & 8.1 & 8.4 & 7.2 & 6.9 \\
2017 & 11.0 & 3.0 & 6.5 & 5.7 & 7.6 & 11.1 \\
2018 & 5.8 & 12.5 & 13.7 & 14.0 & 8.4 & 10.6 \\
2019 & 7.4 & 10.6 & 12.2 & 6.6 & 15.0 & 7.2 \\
Mean \pm STDV & $9.0 \pm 2.4$ & $9.0 \pm 3.6$ & $8.9 \pm 4.0$ & $8.5 \pm 3.2$ & $9.4 \pm 3.2$ & $8.8 \pm 2.0$ \\
$(2015-2019)$ & & & & & & \\
2020 & 8.7 & 11.4 & 14.5 & 28.3 & 20.0 & 21.9 \\
\hline
\end{tabular}

Figure 3 compares the monthly in-hospital first $48 \mathrm{~h}$ death rates for non-elective admissions in 2020 (red line) against each of the five preceding years. Death rates increased rapidly and achieved the pick in April, followed by numbers much higher than average ones in the preceding years (Table 3 ).

Table 3: Increasing monthly first $48 \mathrm{~h}$ mortality rates in 2020 versus average death rates in 2015-2019

\begin{tabular}{lllllll}
\hline $\begin{array}{l}\text { Mortality (\%) } \\
\text { first } 48 \mathrm{~h}\end{array}$ & January & February & March & April & May & June \\
\hline 2015 & 5.6 & 3.3 & 3.3 & 2.7 & 6.9 & 3.5 \\
2016 & 7.1 & 3.5 & 3.4 & 3.9 & 0.8 & 2.1 \\
2017 & 4.9 & 0.6 & 3.9 & 3.4 & 2.3 & 1.7 \\
2018 & 3.8 & 5.8 & 6.9 & 8.6 & 3.2 & 3.8 \\
2019 & 3.9 & 3.5 & 5.2 & 2.9 & 7.1 & 3.2 \\
Mean \pm STDV & $5.1 \pm 1.21$ & $3.3 \pm 1.64$ & $4.5 \pm 1.37$ & $4.3 \pm 2.19$ & $4.0 \pm 2.52$ & $2.8 \pm 0.81$ \\
$(2015-2019)$ & & & & & & \\
2020 & 4.7 & 6.8 & 9.6 & 19.6 & 10.9 & 12.5 \\
\hline
\end{tabular}

Figure 4 compares the monthly in-hospital first $24 \mathrm{~h}$ death rates for non-elective admissions in 2020 (red line) against each of the five preceding years. The curve climbed above $6 \%$ from February and maintaining Plato in the following months above $8 \%$. Death rates were much higher than average ones in the preceding years (Table 4).

Table 4: Increasing monthly first $24 \mathrm{~h}$ mortality rates in 2020 versus average death rates in 2015-2019

\begin{tabular}{lllllll}
\hline $\begin{array}{l}\text { Mortality (\%) } \\
\text { first } 24 \mathrm{~h}\end{array}$ & January & February & March & April & May & June \\
\hline 2015 & & & & & & \\
2016 & 6.0 & 4.1 & 3.3 & 1.8 & 5.8 & 2.9 \\
2017 & 4.3 & 3.5 & 2.7 & 2.6 & 0.0 & 1.4 \\
2018 & 3.0 & 5.2 & 1.3 & 3.4 & 2.3 & 3.4 \\
2019 & 3.1 & 3.0 & 6.0 & 6.0 & 3.0 & 3.2 \\
Mean \pm STDV & $4.2 \pm 1.24$ & $4.0 \pm 0.78$ & $3.6 \pm 1.67$ & $3.7 \pm 1.45$ & $3.4 \pm 2.19$ & $2.9 \pm 0.76$ \\
$(2015-2019)$ & & & & & & \\
2020 & 1.6 & 6.8 & 7.2 & 8.7 & 9.1 & 7.8 \\
\hline
\end{tabular}

The number of hospital admissions in the first 2 months of 2020 was above 100 (Figure 5). A significant decline was observed from March, exceeding the lowest number in April (45). On the opposite, the RT-PCR testing for SARS-CoV-2 detection began at the beginning of April and raised along with the number of admitted patients.

From April 2020, the testing rate of the hospitalized patients was above $30 \%$ (Table 5). The patients that died we also partly tested in April 38\%, May $27 \%$, and $57 \%$ in June.

Table 5: Admissions, rates of RT-PCR tests for SARS-CoV-2 in all and the dead patients

\begin{tabular}{lllllll}
\hline 2020 & January & February & March & April & May & June \\
\hline All admissions & 134 & 104 & 91 & 45 & 55 & 64 \\
$\begin{array}{l}\text { All SARS-CoV-2 RT-PCR } \\
\text { tests (rate) }\end{array}$ & 0 & 0 & 0 & $15(33 \%)$ & $17(31 \%)$ & $25(39 \%)$ \\
$\begin{array}{l}\text { All deaths } \\
\begin{array}{l}\text { SARS-CoV-2 RT-PCR } \\
\text { tests in dead patients (rate) }\end{array}\end{array}$ & 11 & 10 & 12 & 13 & 11 & 14 \\
\hline $\begin{array}{l}\text { SARS-CoV-2: Severe acute respiratory syndrome coronavirus 2, RT-PCR: Reverse transcriptase- } \\
\text { polymerase chain reaction }\end{array}$ & & & & & &
\end{tabular}

In the first 6 months of 2020, there were 28 patients that died in the first $24 \mathrm{~h}$ of the hospital stay and only $2(7.1 \%)$ were being tested for SARS-CoV-2 (Figure 6). Out of 46 patients that have died in the first $48 \mathrm{~h}$ of the hospital stay, $10(21.7 \%)$ have been tested, and only one patient was positive. Other four positive patients were transferred to dedicated COVID19 hospitals.

\section{Discussion}

During the COVID-19 pandemic, excess mortality was observed in many European countries [14] and reported in recent publications from all over the world [15], varying by states and regions. The analyzed data on excess mortality (the numbers of deaths over 


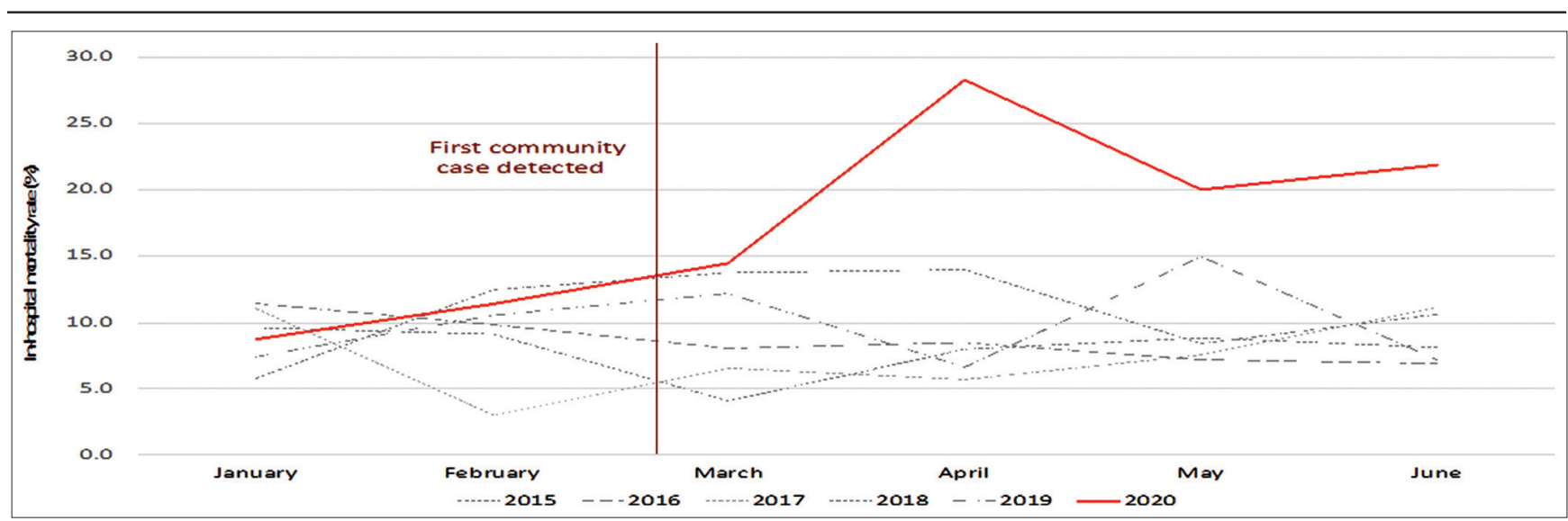

Figure 2: Monthly death rates in 2020 compared to the five preceding years for non-elective admissions

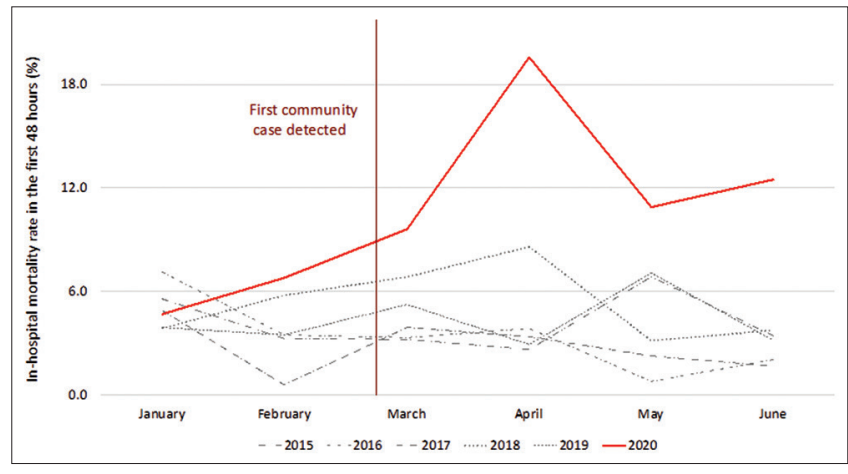

Figure 3: Monthly death rates in the first 48 h 2020 compared to the five preceding years for non-elective admissions

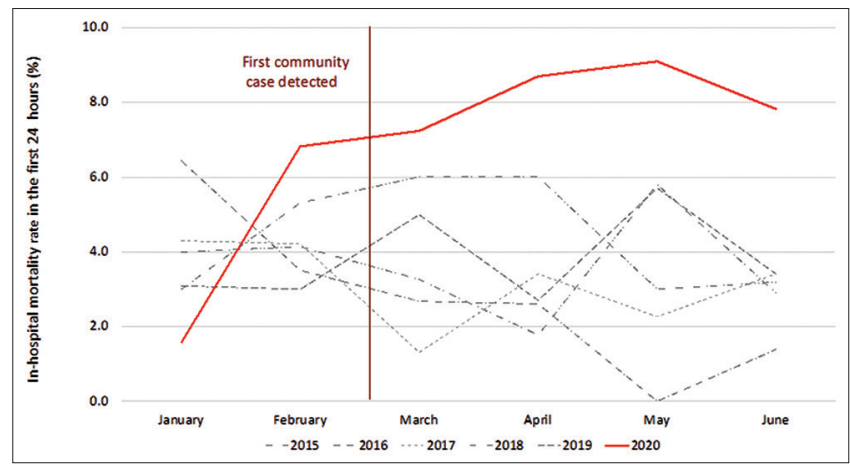

Figure 4: Monthly death rates in the first $24 \mathrm{~h} 2020$ compared to the five preceding years for non-elective admissions

and above the historical average) across the globe have shown that numbers of deaths in some countries were more than $50 \%$ higher than usual [14]. In many countries, these excess deaths exceed reported numbers of COVID-19 deaths by large margins. In New York State, all-cause mortality rose from 2- to 7-fold above baseline at the peak of the pandemic, whereas $26 \%$ were unattributed to COVID-19 [16].

In this study, we have compared the in-hospital mortality rates in one nephrology clinic from the previous 5 years to the current year of 2020. The excess mortality exceeded $70 \%$, resulting from sudden divergence from the excepted pattern, including decline in patients' hospitalizations and higher fatalities. This

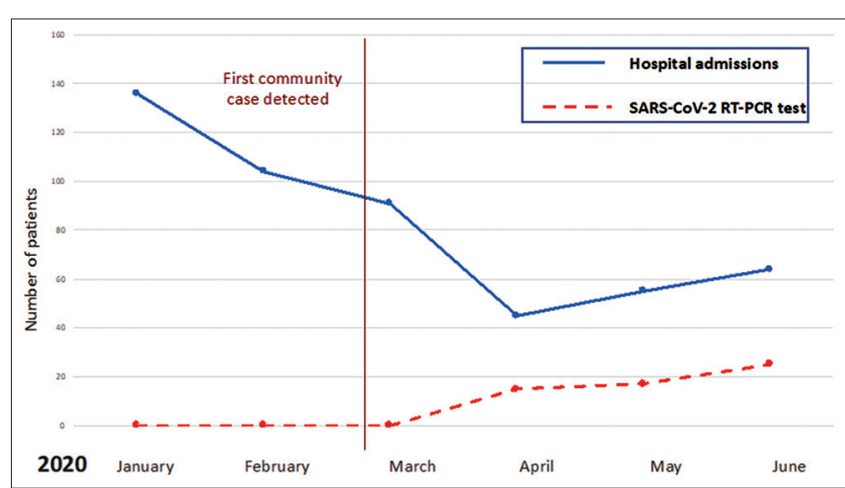

Figure 5: Hospital admissions and polymerase chain reaction testing for severe acute respiratory syndrome coronavirus-2 detection in hospitalized patients in 2020

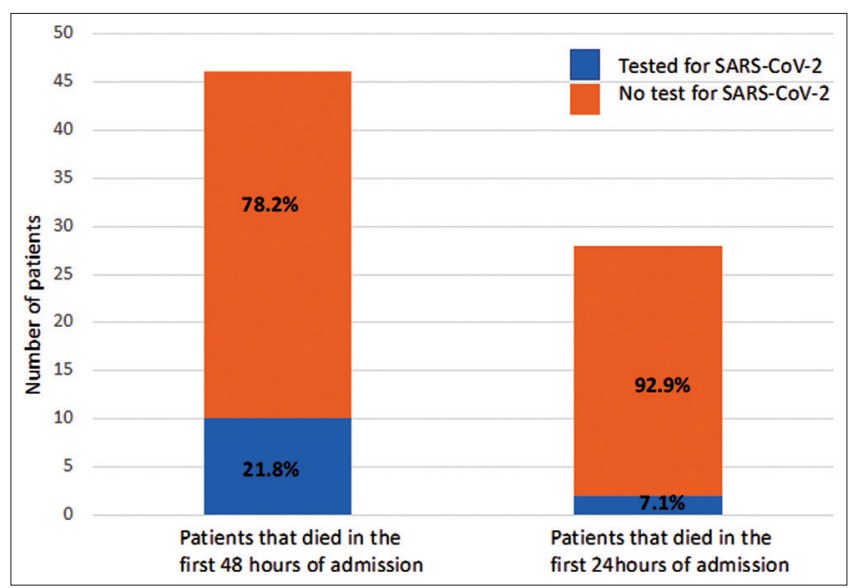

Figure 6: Proportions of performed severe acute respiratory syndrome coronavirus-2 tests regarding the time of the death

high mortality might be explained by several factors: Stress, avoidance of the health care system considering potential COVID-19 infection, delayed or unrecognized symptoms of kidney function deterioration with late admissions, and diagnostic uncertainties. We also have to account for the health care organizing changes.

Crises are generating stress to the general and populations with chronic diseases. During COVID-19 pandemic, WHO addressed the issue on global mental health and psychosocial considerations [17]. Stress implications for CKD initiation, progression, complications, 
and premature mortality are also well known [18]. Global lockdown, fear, lack of family connections, and low educational level of symptoms recognition might have caused delayed hospitalizations of patients with severe conditions. Our previous 5 years mortality study showed that more than $40 \%$ of dead patients from CKD were not aware of the disease or referred to a nephrologist ever [4]. Despite all the provided information about COVID-19, more than one-third of deaths from COVID-19 infection in our country occurred in the first $1-5$ days after admission at hospitals and this high mortality was most probably due to the late referral or previous patients' reluctance for timely hospitalization [19]. However, patients educated and followed for CKD at our clinic, and those initiated on dialysis were timely referred even during COVID-19 lockdowns. This can be observed from the stable number of patients starting dialysis in the previous 5 years and during 2020. At best of our knowledge, there is no other publication on specific nephrology patients' mortality during this crisis to compare our data with and that is one limitation of our study. On the other hand, a dramatic hospital admission reduction for patients with acute myocardial infarctions has been witnessed in Asia [20], Europe [21], [22] and North America [23], associated with a parallel increase in hospital fatality and complication rates [24]. Those studies explained this phenomenon also by patients' related factors as stress, health care system reorganizations, and unrecognized COVID-19 deaths, referring to the need of education as prevention [25].

The highest pick of mortality at our clinic was observed in April, which is in line with mortality picks in nearly all European countries suffering from the outbreak in March 2020 and global lockdown [14]. Furthermore, $64 \%$ of all deaths occurred in only $48 \mathrm{~h}$ after admission. Considering the limited time before death, the number of first and repeated tests performed and sensitivity of the tests, there have might been a number of deaths caused by the virus that were not counted. One reason might be the detectability and clearance of the viral RNA [26]: Patients with mild symptomatology do not refer to the doctor in a timely fashion for being tested; also, the virus may be detectable in the upper respiratory tract 1-3 days before the onset of symptoms with the highest concentration around the time of symptom onset, and clearance of the virus for several days in some patients, while in other patients it can be detected for several weeks even months. As a limitation of our study, many patients were not tested, and in those that were tested, only one test was performed because of death. According to literature [26], [27] and the "National guidance for interpretation of the COVID-19 test results" published by the IPH since March 2020 [28], subsequent testing is recommended for firstly negative patients as well as considering other types of samples, not only from the upper respiratory tract. Recent systematic reviews of the accuracy of SARS-CoV-2 tests reported false-negative rates of between $2 \%$ and $29 \%$ (equating to sensitivity of $71-98 \%$ ), based on negative RT-PCR tests which were positive on repeat testing [29], [30].
Furthermore, accuracy of viral RNA swabs in clinical practice varied depending on the site and quality of sampling [31], especially in patients with intestinal form of COVID-19 infection [32], where the respiratory infection was not confirmed by nasal swabs detection. Considering all these findings, we speculate that there might be some unrecognized or unconfirmed probable COVID deaths [33] among our patients, which implies a need of further analysis. If some of the patients were recognized with COVID-19 infection, part of them might be transferred to dedicated COVID-19 clinics, and the mortality rate would be lower, which also limits our study.

Nevertheless, the importance of our study is in the pragmatic approach by seeing the real striking data on the higher mortality rates during the pandemic from the registry data which elucidates the need of more knowledge about the novel virus and global pandemic circumstances.

\section{Conclusion}

In this study, we have provided clear evidence of high excess mortality at our nephrology clinic during the $1^{\text {st }}$ months of the COVID-19 pandemic. Severely ill patients mostly died in the early $48 \mathrm{~h}$ of admission, limiting the time for diagnostic and therapeutic options. The delayed referral of patients due to the patient and health care system-related factors might partially explain the excess mortality during pandemic crises. Education of patients in recognizing symptoms of life-threatening conditions and seeks appropriate care on time remains crucial during the COVID-19 pandemic. Further analysis is needed to estimate unrecognized probable COVID-19 deaths.

\section{References}

1. World Health Organization. Director-general's Opening Remarks at the Media Briefing on COVID-19 2020. Geneva: World Health Organization; 2020. Available from: http://ww.who. int. [Last accessed on 2020 Mar 11]. https://doi.org/10.1093/ ww/9780199540884.013.u51992

2. COVID-19 Dashboard by the Center for Systems Science and Engineering (CSSE) at Johns Hopkins University (JHU). ArcGIS. Johns Hopkins University. Available from: http://www. gisanddata.maps.argis.com. [Last accessed on 2020 Aug 03]. https://doi.org/10.21203/rs.3.rs-15447/v1

3. Checchi F, Roberts L. Interpreting and Using Mortality Data in Humanitarian Emergencies. Humanitarian Practice Network; 2005. Available from: https://odihpn.org/wp-content/ uploads/2005/09/networkpaper052.pdf. [Last accessed on 2020 Sep 06].

4. Trajceska L, Grcevska L, Sikole A, Stojceva O, Spasovski G, Tozija L, et al. Quality of health care and mortality: Three years of experience. Acta Morphol. 2018;15(2):14-22. 
5. Stojceva-Taneva O, Selim G. Vascular access in hemodialysis patients-registry data. Hippokratia. 2014;18(3):209-11.

PMid:25694752

6. Trajceska L, Andreevska GS, Dzekova P, Nikolov I, Selim G, Spasovski, et al. Complications and risks of percutaneous renal biopsy. Open Access Maced J Med Sci. 2019;7(6):992-5 https://doi.org/10.3889/oamjms.2019.226

PMid:30976347

7. Severova G, Nikolov I, Sikole A, Cakalaroski K, Popov Z, Ivanovski N. Clinical importance of non-donor-specific HLA antibodies and possible impact on graft histology in kidney transplant recipients-12 months protocol biopsy study. Transplantation. 2018;102:484. https://doi.org/10.1097/01. tp.0000543294.46098.2d

8. Kramer A, Pippias M, Noordzij M, Stel S, Andrusev A, AparicioMadre $\mathrm{M}$, et al. The European renal association-European dialysis and transplant association (ERA-EDTA) registry annual report 2016: A summary. Clin Kidney J. 2019;12(5):702-20. https://doi.org/10.1093/ckj/sfz011

PMid:29423210

9. Information, Guidelines, Questions and Answers Regarding Covid-19 Virus. Available from: http://www.zdravstvo.gov.mk/ corona-virus. [Last accessed on 2020 Aug 17].

10. MOJ TERMIN. Available form: http://www.mojtermin.mk/ health_workers.

11. Lukanovska T, Dimkovski V. Annual Report for 2010. Skopje: Health Insurance Fund Macedonia; 2011. Available from: http:// www.fzo.org.mk. [Last accessed on 2020 Mar 18].

12. Census of Population, Households and Dwellings in the Republic of Macedonia; 2002. Available from: http://www.stat. gov.mk/publikacii/knigaX.pdf. [Last accessed on 2020 Aug 18].

13. Country and Technical Guidance-coronavirus Disease (COVID19). Available from: https://www.who.int/emergencies/diseases/ novel-coronavirus-2019/technical-guidance-publications-b89ccbdf5b386938-MentalHealth-2020.1. [Last accessed on 2020 Sep 11].

14. Real-time All-cause Mortality Data: EuroMomo Project. Available from: https://www.euromomo.eu. [Last accessed on 2020 Sep 11].

15. Coronavirus Tracked: The Latest Figures as Countries Fight Covid-19 Resurgence. Free to Read. Available from: http:// www.ft.com/content/a2901ce8-5eb7-4633-b89c-cbdf5b386938MentalHealth-2020.1. [Last accessed on 2020 Sep 18].

16. Weinberger DM, Chen J, Cohen T, Crawford W, Mostashari F, Olson D, et al. Estimation of excess deaths associated with the COVID-19 pandemic in the united states, March to May 2020. JAMA Intern Med. 2020;180(10):1336-44. https://doi. org/10.1001/jamainternmed.2020.3391 PMid:32609310

17. WHO Mental Health and Psychosocial Considerations During the COVID-19 Outbreak. Available from: https://www.who.int/ publications/i/item/WHO-2019-nCoV-MentalHealth-2020.1. [Last accessed on 2020 Mar 18].

18. Bruce MA, Griffith DM, Thorpe RJ Jr. Stress and the kidney. Adv Chronic Kidney Dis. 2015;22(1):46-53. PMid:25573512

19. Ministry of Health Press Conference; 2020. Available from: https://www.slobodnaevropa.mk/a/30680414.html. [Last accessed on 2020 Jun 19].

20. Tam CF, Cheung KS, Lam S, Wong A, Yung A, Sze M, et al. Impact of coronavirus disease 2019 (COVID-19) outbreak on ST-segment-elevation myocardial infarction care in Hong Kong China. Circ Cardiovasc Qual Outcomes. 2020;13(4):e006631. https://doi.org/10.1161/circoutcomes.120.006631

\section{PMid:32182131}

21. De Filippo O, D'Ascenzo F, Angelini F, Bocchino P, Conrotto F Saglietto A, et al. Reduced rate of hospital admissions for ACS during Covid-19 outbreak in Northern Italy. N Engl J Med. 2020;383:88-9.

PMid:32343497

22. Rodriguez-Leor O, Cid-Alvarez B, Ojeda S, Martín-Moreiras J, Rumoroso J, López-Palop R, et al. Impact of the COVID-19 pandemic on interventional cardiology activity in Spain. REC Interv Cardiol. 2020;2:82-9. https://doi.org/10.24875/recice. m20000123

23. Garcia S, Albaghdadi S, Meraj M, Schmidt C, Garberich R, Jaffer FA, et al. Reduction in ST-segment elevation cardiac catheterization laboratory activations in the United States during COVID-19 pandemic. J Am Coll Cardiol. 2020;75(22):2871-2. https://doi.org/10.1016/j.jacc.2020.04.011

PMid:32283124

24. De Rosa S, Spaccarotella C, Basso C, Calabrò P, CurcioA, Filardi P, et al. Reduction of hospitalizations for myocardial infarction in Italy in the COVID-19 era. Eur Heart J. 2020;41(22):2083-8.

PMid:32412631

25. Buono A, Ammirati E. ST-elevation acute myocardial infarction during COVID-19 pandemic: Are we missing the boat? Int J Cardiol Heart Vasc. 2020;29:100578. https://doi.org/10.1016/j. ijcha.2020.100578

PMid:32665971

26. WHO Interim Guidance Diagnostic Testing for SARS-CoV-2 Available from: https://www.who.int/publications/i/item/diagnostictesting-for-sars-cov-2. [Last accessed on 2020 Jul 10].

27. National Guidance for Interpretation of the COVID-19 Test Results. Available from: http://www.iph.mk/upatstvo-za-nacinna-interpretacija-na-rezultati-na-testovi-za-covid-19/. [Last accessed on 2020 Jun 08].

28. First Affiliated Hospital of Zhejiang University School of Medicine. Handbook of COVID-19 Prevention and Treatment 2020. Available from: https://esge.org/documents/Handbook of COVID-19 Prevention and Treatment.pdf. [Last accessed on 2020 Jun 07].

29. Arevalo-Rodriguez I, Buitrago-Garcia D, Simancas-Racines D, Zambrano-Achig P, Del Campo R, Ciapponi A, et al. Falsenegative results of initial RT-PCR assays for COVID-19: A systematic review. PLoS One. 2020;15(12):e0242958. http:// doi:10.1371/journal.pone.0242958

30. Kucirka LM, Lauer SA, Laeyendecker O, Boon D, Lessler J. Variation in false-negative rate of reverse transcriptase polymerase chain reaction-based SARS-CoV-2 tests by time since exposure. Ann Intern Med. 2020;173(4):262-7. https://doi. org $/ 10.7326 / \mathrm{m} 20-1495$

PMid:32422057

31. Wang W, Xu Y, Gao R, Lu R, Han K, Wu G, et al. Detection of SARS-CoV-2 in different types of clinical specimens. JAMA. 2020;323(18):1843-4. https://doi.org/10.1001/jama.2020.3786 PMid:32159775

32. Xiao F, Tang M, Zheng $\mathrm{X}$, Liu $\mathrm{Y}$, Li X, Shan H. Evidence for gastrointestinal infection of SARS-CoV-2. Gastroenterology. 2020;158(6):1831-3.e3. gastro.2020.02.055 PMid:32142773

33. Standardized Surveillance Case Definition and National Notification for 2019 Novel Coronavirus Disease (COVID-19). Available from: https://cdn.ymaws.com/www.cste.org/resource/ resmgr/ps/positionstatement2020/Interim-20-ID-01_COVID19_NO.pdf. [Last accessed on 2020 Jun 06]. 